\title{
Dry Sliding Wear Behaviour of SiC Particles Reinforced Zinc-Aluminium (ZA43) Alloy Metal Matrix Composites
}

\author{
Rajaneesh N. Marigoudar ${ }^{1 *}$, Kanakuppi Sadashivappa ${ }^{2}$ \\ ${ }^{1}$ Lecturer, Mechanical Engineering Department, \\ GM Institute of Technology, Davangere 577006, Karnataka, India \\ ${ }^{2}$ Professor, Department of IPE, Bapuji Institute of Engineering \& Technology, \\ Davangere 577004, Karnataka, India \\ *Corresponding Author: rajaneeshmarigoudar@gmail.com
}

\begin{abstract}
The present paper reveals the wear behaviour of Zinc - Aluminium alloy reinforced with SiC particulate metal matrix composite. The composite is prepared using liquid metallurgy technique. The unlubricated pin-on disc wear test is conducted to find the wear behaviour of the ZA43 alloy based composite. The sliding wear test is conducted for different load, speed and time. The result reveals that wear rates of composite is reduced as reinforcement increases. For the same working conditions wear rate increases with increasing load and with increasing speed. The tested samples are examined by taking micro structure photos and analyzed for the type of wear. Dominating wear types observed are delamination and abrasion.
\end{abstract}

Keywords: SiC/ ZA43 composite, particulate metal matrix composite, Zinc-Aluminium alloy, abrasive wear, delamination.

\section{INTRODUCTION}

The metal matrix composites (MMCs) reinforced with ceramic dispersoids, are showing properties like light weight and high strength. Because of the properties, MMCs captured large area of applications. The MMCs posses excellent mechanical and tribological properties and are considered as potential engineering materials for various tribological applications [15]. Several researchers have worked on sliding wear mechanism of MMCs reinforced with ceramic particulates like $\mathrm{SiCp}, \mathrm{Al}_{2} \mathrm{O}_{3}$ and even short fibers etc, and have observed improvement in wear and abrasion resistance [6]. Further, the increased percentage of these reinforcements contributed in increased hardness and density of the composites [11]. Wear is 
a common mechanism which is observed in machine tools and its components, which is a slow process. However, if the rate of wear on particular machine component is high, so that it requires frequent repair and replacement, then it may constitute a wear problem. ZA based alloy reinforced with ceramic particles exhibit good wear resistant properties [7]. The MMC is tested under various conditions by varying parameters like speed and load. In particular ZA based MMC shows higher abrasion and wear resistant under variable conditions [10]. In the present study the composite is prepared by stir casting technique. The specimen is subjected to dry sliding condition using pin on disc wear testing machine [9]. The worn-out specimen is analyzed for nature of wear.

\section{MATERIALS AND EXPERIMENTATION}

The chemical composition of ZA43 base alloy is shown in Table 1. Aluminium which is in higher percentage responsible for increase in hardness of base alloy [8], further increase in hardness is due to reinforcement in MMC.

Table 1 : Composition of ZA43 alloy (wt. \%)

\begin{tabular}{cc}
\hline Element & Percentage \\
\hline $\mathrm{Al}$ & 43 \\
$\mathrm{Cu}$ & 2.5 \\
$\mathrm{Mg}$ & 0.02 \\
$\mathrm{Fe}$ & 0.012 \\
$\mathrm{Zn}$ & Balance \\
\hline
\end{tabular}

SiC particles are introduced in to the matrix by liquid metallurgy technique shown in Fig. 1. The percentage of $\mathrm{SiC}(30 \mu)$ is varied between $1 \%-5 \%$ in steps of $1 \%$ by weight. The matrix material is heated above its melting temperature i.e. $750^{\circ} \mathrm{C}$. The molten matrix is stirred using stirring mechanism; meanwhile pre heated $\mathrm{SiC}$ particles are introduced into the molten matrix. Pre heating of $\mathrm{SiC}$ improves the wettability with molten metal and magnesium in the small percentage also improves the wettability [4]. Stirring of the mixture is continued till whirl is formed and uniform distribution of particles takes place. This molten mixture is poured into cast iron die. Mixture is allowed in the die to attain the room temperature. The solidified specimen is removed from the die and tested. Stirring blades are coated with zircon which reduces the diffusion of steel in to the molten metal.

Wear testing specimen is casted according to ASTM G99. A pin on disc wear testing configuration is used to check wear properties of composite specimen. The specimen is rubbed against rotating hard steel disc without any lubricant. Dry sliding method is followed. Variable parameters such as speed, which is varied between $1.2 \mathrm{~m} / \mathrm{s}$ to $5.1 \mathrm{~m} / \mathrm{s}$ and load is varied between $10 \mathrm{~N}$ to $40 \mathrm{~N}$. Common track diameter of $120 \mathrm{~mm}$ is used to test the specimen. After testing, the specimen is removed from the machine and weighed. Difference in initial and final weight gives the loss of material in turn wear rate of the material. The specimen is 
weighed using electronic balance. Tests are conducted at normal room temperature. The principal objective of investigation was to study the effect of variation of normal load, sliding velocity and percentage $\mathrm{SiC}$ on wear rate.

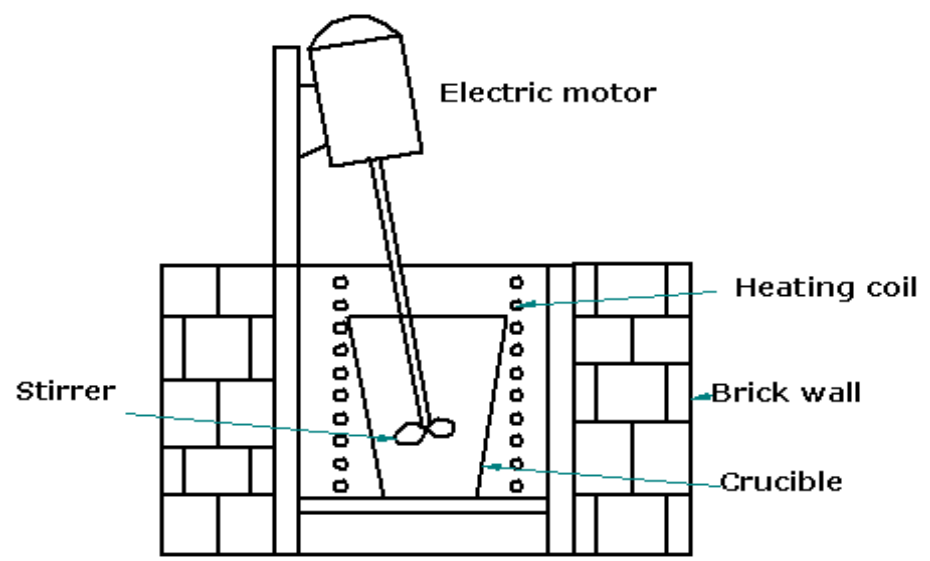

Figure 1. Stir casting setup for MMC fabrication

\section{RESULTS AND DISCUSSION}

Abrasive wear has been defined as the displacement of material caused by hard particles or hard proturberances where these hard particles are forced against and moving along a solid surface. By incorporating the $\mathrm{SiC}$ particles in to the matrix, the sliding wear properties are enhanced [1, 2]. The hardness of the specimen increases and fluidity decreases. The effect of variable load and speed on specimen wear is checked against variable reinforcement percentage.

The effect of applied normal load on the MMC with different SiC reinforcement percentage is shown in Figure 2. In this test, for constant speed of $3.7 \mathrm{~m} / \mathrm{s}$, load is increased in steps of $10 \mathrm{~N}$. The test is conducted for normal loads of $10,20,30$ and $40 \mathrm{~N}$. It is observed that wear of the composite specimen decreases with increase in $\mathrm{SiC}$ percentage $[9,10]$. This happens because of $\mathrm{SiC}$, which is hard material which improves the hardness. For specimen with 1\% reinforcement with $10 \mathrm{~N}$ load, almost wear is negligible. As load is increased, increase in wear is observed. Decreasing trend is observed with increase in reinforcement. For 5\% reinforcement load is increase, less weight loss is observed. 


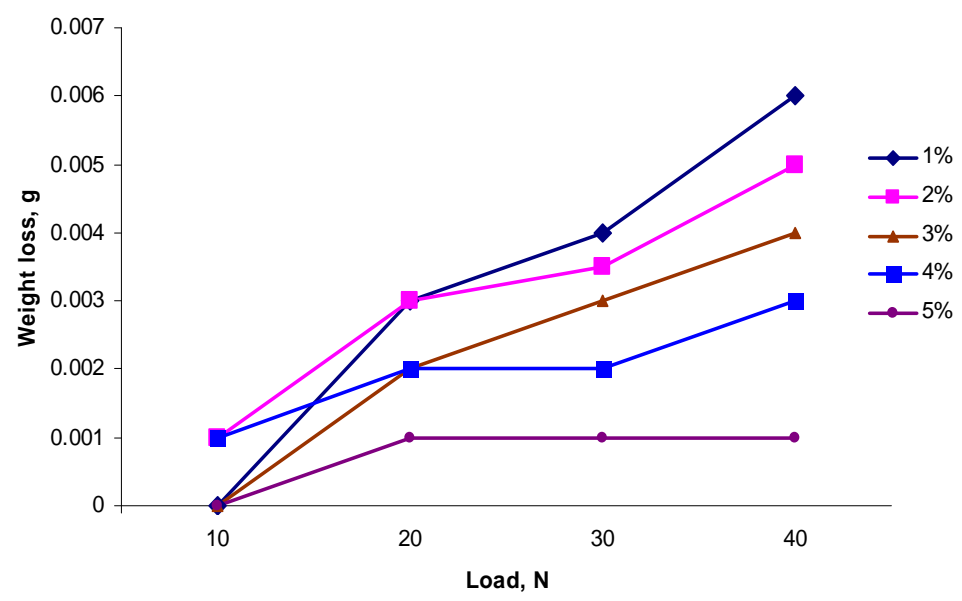

Figure 2. Variation of weight loss with applied load

For a load of $40 \mathrm{~N}$ microstructure photographs of the specimen with $2 \%$ and $5 \%$ reinforcement subjected to different loading condition is taken. It is observed form the Figure 3(a) and 3(b) that at grooves are formed in the direction of rotation of disc. Due to friction, increase in temperature is observed, hence softening of the specimen is observed. Delamination of the specimen is observed and deep grooves are formed on the surface. Sometime particle pull-out is observed. Wear debris are also observed.
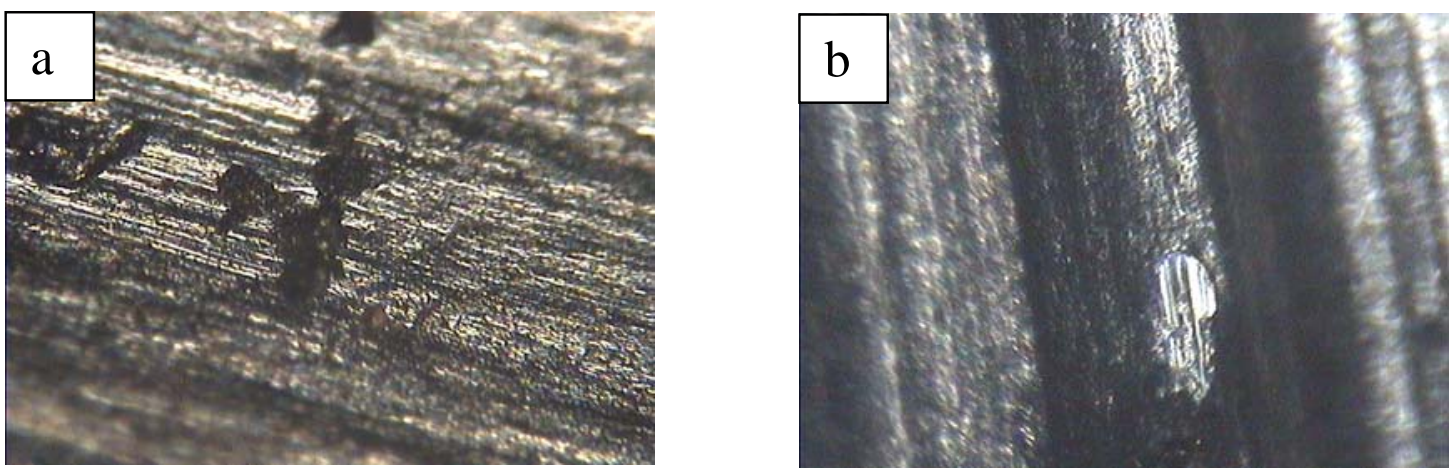

Figure 3. Microstructure photograph of worn surface when subjected to varying load (a) $2 \% \mathrm{SiC}$ and load of $40 \mathrm{~N}$ and (b) 5\% SiC with load of $40 \mathrm{~N}$.

The effect of varying speed on MMC with varying SiC is shown in Figure 4. Load is kept constant at $40 \mathrm{~N}$ and speed is varied 1.2, 2.5, 3.7 and $5.1 \mathrm{~m} / \mathrm{s}$. From the graph, it is observed that higher wear of MMC with increase in speed. For 1\% reinforcement, as speed is increased higher material loss is observed. For same conditions, when reinforcement is increased to $5 \%$, less material loss is observed. Again this is due to increase in hardness of MMC. Hard reinforcement is responsible for increase in hardness. 


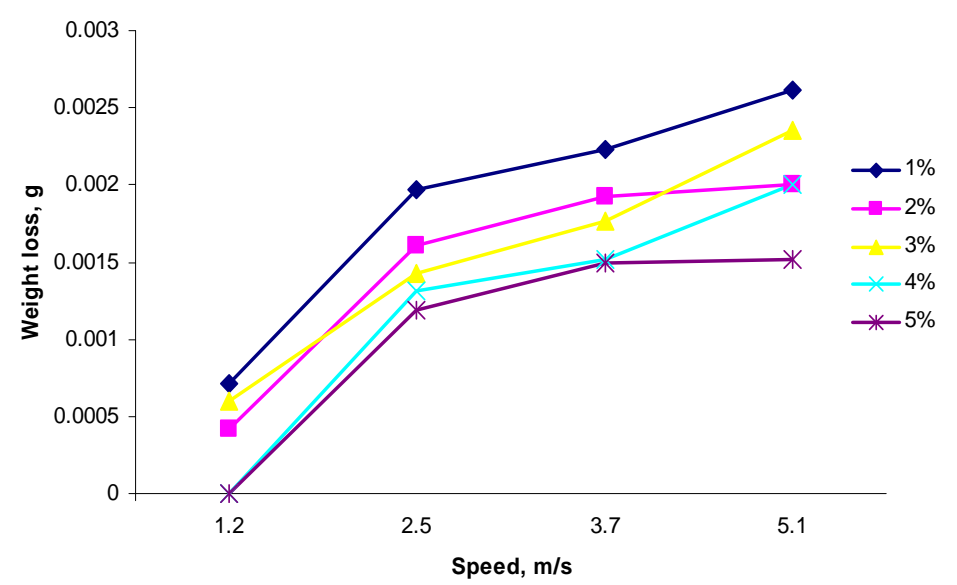

Figure 4. Variation of weight loss with increasing speed

Microstructure photographs of the specimen with 2\% and 5\% SiC are taken. The Figure 5(a) for $1.2 \mathrm{~m} / \mathrm{s}$ speed and 5 (b) for $5.1 \mathrm{~m} / \mathrm{s}$, reveals that material removal and worn-out surface of composite with $2 \%$ and $5 \%$. As speed is gradually increased, initially small scratches are formed on the surface and gradually they get converted in to grooves. Even small craters are also formed because of the delamination. Scissoring action is observed on the surface. The grooves formed on the surface are in the direction of sliding.
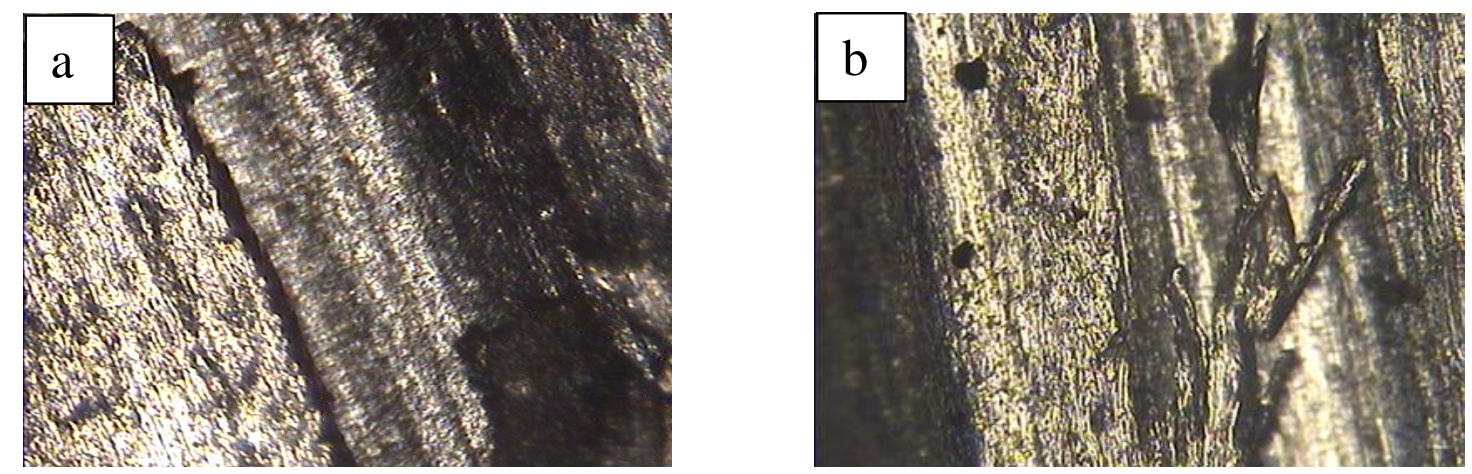

Figure 5. Microstructure photograph of worn surface with $2 \%$ and $5 \%$ SiC subjected to varying speed (a) Speed $1.2 \mathrm{~m} / \mathrm{s}$ and load of $40 \mathrm{~N}$ (b) Speed $5.1 \mathrm{~m} / \mathrm{s}$ and load of $40 \mathrm{~N}$.

It is observed from the microstructure image, loss of material is due to high friction between MMC and rotating disc. In both the conditions that, predominant wear occur due to delamination and abrasion. It is also observed that material adhere to the disc due to high temperature and even undergo plastic deformation some time material become soft and it may melt. 


\section{CONCLUSION}

This paper reports the wear properties of ZA43 alloy reinforced with SiC particulate MMC. Zinc based MMC shows lower co-efficient of friction under dry sliding condition. The MMC is prepared using liquid metallurgy technique. The standard specimen prepared is subjected to dry sliding wear test.

It is observed that the composite with $1 \%$ reinforcement at low load of $10 \mathrm{~N}$, shows less wear and as load is increased to $40 \mathrm{~N}$, material exhibit higher wear. For the same testing conditions, as reinforcement is increased to $5 \%$, decrease in wear is observed.

For constant load of $40 \mathrm{~N}$ and at speed of $1.2 \mathrm{~m} / \mathrm{s}$, composite with $1 \%$ reinforcement shows lower wear and as speed is increased wear of the specimen increases. As the speed is increased to $5.1 \mathrm{~m} / \mathrm{s}$, wear increases. For the same testing conditions, as reinforcement is increased to $5 \%$, wear decreases.

The presence of reinforcement restricts the growth of micro cracks and delamination. Combination of delamination and abrasive wear is observed during the test. Sometimes adhesion and melting of the specimen are also observed.

\section{REFERENCES}

1. J K M Kwok, S C Lim, "High speed tribological properties of Al/SiC composites: I Frictional and wear rate characteristics”, Composites Science and Technology, 1999, 59, $55-63$.

2. J K M Kwok, S C Lim, "High speed tribological properties of Al/SiC composites: II wear mechanisms”, Composites Science and Technology, 1999, 59, 65 - 75.

3. G Ranganath, S C Sharma, M Krishna, "Dry sliding wear of garnet reinforced zinc/aluminium metal matrix composites”, Wear, 2001, 251, 1408 - 1413

4. S C Lim, M Gupta, L Ren, J K M Kwok, "The tribological properties of Al-Cu/SiC metal matrix composites fabricated using the rheocasting technique”, Journal of material processing and Technology, 1999, 90, 591-596

5. Gencaga Purcek, Temel Savaskan, Samuel Murphy, "Dry sliding friction and wear properties of zinc based alloy”, Wear, 2002, 252, 894 - 901

6. Xie Xianquing, Zhang Di, Liu Jinshui, “Thermal expansion properties of TiC particle reinforced ZA43 matrix composite”, Materials and Design, 2001, 22, 157 - 162

7. S Das, "Development of aluminum alloy composites for engineering applications", Trans. Indian Inst. Met, 2004, 57, 325 - 334

8. M T Abou El-khair, A Daoud, A Ismail, "Effect of different Al contents on the microstructure, tensile and wear properties of $\mathrm{Zn}$ - based alloy”, Materials Letters, 2004, 58, $1754-1760$

9. M Ramachandra, K Radhakrishna, "Sliding wear, slurry erosive, and corrosive wear of aluminium / SiC composite”, Materials Science - Poland, 2006, 24, 333 - 349

10. K H W Seah, S C Sharma, P R Rao, B M Girish, "Mechanical properties of as cast and heat treated ZA-27 / silicon carbide particulate composite”, Materials and Design, 1995, 16, $277-281$ 
11. M Manoharan, M Gupta, "Effect of silicon carbide volume fraction on the wok hardening behaviour of thermomechanically processed aluminium based metal matrix composites”, Composites Part B, 30(1999), 107 - 112 